\title{
Plasmacytoid Dendritic Cells in Cutaneous Disorders
}

\author{
William Vermi • Raffaella Vescovi • Fabio Facchetti
}

Published online: 30 December 2012

(C) Springer Science+Business Media New York 2012

\begin{abstract}
Skin immune surveillance is granted by a complex contingent of sentinel innate immune cells with antigenpresenting function. The latter include Langerhans cells (LCs), multiple subsets of dermal dendritic cells (DDCs), and dermal macrophages (DMs). As for other peripheral nonlymphoid tissues, the microenvironment of the normal skin is lacking plasmacytoid dendritic cells (PDCs), a circulating DCs subset that mainly populates primary and secondary lymphoid organs. PDCs accumulation in the skin is observed in different cutaneous inflammatory disorders, including autoimmunity and viral infection. This review will summarize current knowledge on the biology of skin DCs and will highlight the functional role of PDCs in the complex microenvironment of well-characterized cutaneous disease models.
\end{abstract}

Keywords Plasmacytoid dendritic cells $\cdot$ Psoriasis $\cdot$ Lupus erythematosus $\cdot$ IFN-DC $\cdot$ Interferon $\cdot$ TLR $\cdot$ Molluscum contagiosum virus $\cdot$ Blastic plasmacytoid dendritic cell neoplasm

W. Vermi $\cdot$ R. Vescovi $\cdot$ F. Facchetti

Department of Molecular and Translational Medicine,

Section of Pathology, University of Brescia School of Medicine, Brescia, Italy

W. Vermi

Department of Pathology and Immunology, Washington

University School of Medicine, Saint Louis, MO, USA

W. Vermi $(\bowtie)$

I Servizio di Anatomia Patologica, Spedali Civili di Brescia,

Piazzale Spedali Civili, 1,

25123 Brescia, Italy

e-mail: vermi@med.unibs.it

W. Vermi

e-mail: william.vermi@gmail.com

\author{
Abbreviation \\ DCs Dendritic cells \\ DDCs Dermal dendritic cells \\ DM $\Phi$ Dermal macrophages \\ PDCs Plasmacytoid dendritic cells \\ IFN Interferon \\ IFN-I Type I interferon \\ TLR Toll-like receptor \\ BPDCN Blastic plasmacytoid dendritic cell neoplasm
}

\section{Introduction}

The skin-associated immune system protects the host against a different array of external and endogenous insults. Immune cells of the skin have a significant role in the organization of the first line of defense by triggering microbicidal mechanisms and activating the inflammatory response. Among innate components of the immune system, dendritic cells (DCs) consist of a heterogeneous population of leukocytes that can direct adaptive T- and B-cell immune responses to different antigens. With some potential exception, human DCs are mostly bone marrow derived $\mathrm{CD}^{+} 5^{+} \mathrm{MHC}^{-\mathrm{II}^{+}}$cells lacking markers of lineage, such as CD3, CD14, CD16, CD19, and CD56. Different DCs populations have been classified based on their dominant location (lymphoid organs DCs, intraepithelial and interstitial DCs in nonlymphoid peripheral tissues), presumed origin (myeloid DCs and plasmacytoid DCs [PDCs]), or functional properties (e.g., regulatory, tolerogenic). In the skin, different resident DCs subsets can be identified in the epidermis and dermis. In addition, circulating DCs can be recruited to the site of inflammation in various skin disorders. We revise the recent discoveries on the DCs repertoire of the normal human skin and highlight the role of PDCs in cutaneous diseases. 


\section{Dendritic Cell Populations in Normal Skin. What's New on the Shelf?}

DCs are important sentinels of skin immune system. Expression of MHC-II molecules in normal skin identifies a complex contingent of professional antigen-presenting cells, including DCs and dermal macrophages (DMs; Fig. 1).
Intraepidermal DCs correspond to the unique Langerhans cells (LCs) population that can be easily identified on section by the expression of a panel of markers (e.g., S100 protein, CD1a, E-caderin), including the recently identified Birbeck granules associated protein Langerin (Fig. 1). In the skin, stellate LCs are regularly found in the suprabasal layers of the epidermis in close contact with keratinocytes.
Fig. 1 DCs markers in human normal skin. Formalin-fixed human skin sections are stained as labeled (revealed by DAB, brown). Sections are counterstained with Meyer's hematoxylin. Magnification $100 \times$ and $400 \times$ (insert)
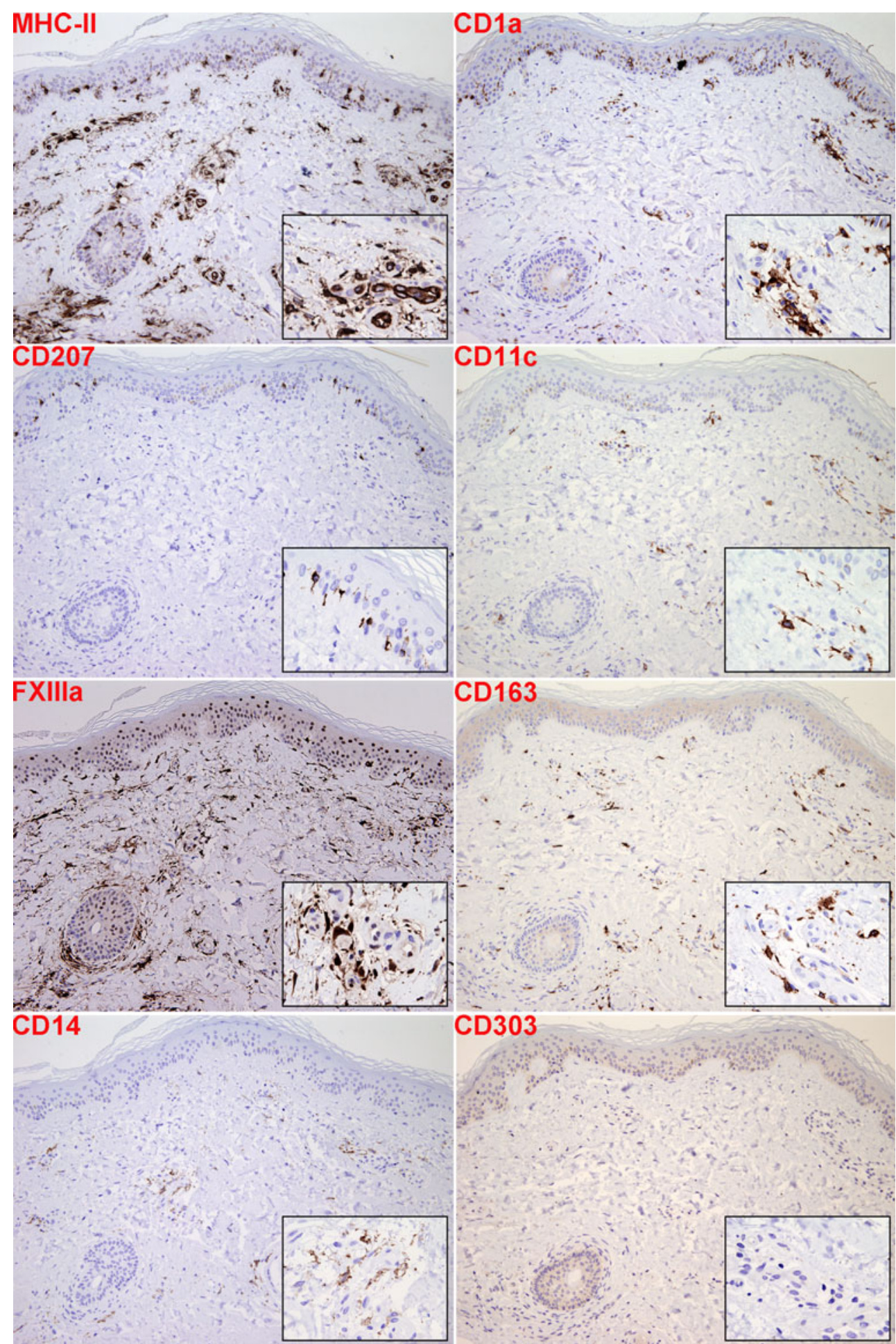
Upon antigen encounter, they migrate via lymphatics to the T-cell area of draining lymph nodes to regulate skin adaptive T-cell immune responses to different pathogens. Although LCs represent one the most well studied antigen-presenting cell population, it is still not completely understood whether they elicits T-cell activation or tolerance $[1,2]$. We recently reported that interleukin (IL)-34, the alternative CSF1R ligand, is abundantly produced by skin keratinocytes and selectively directs the developmental program of LCs [3]. Significantly, IL-34-deficient mice lack LCs and show an attenuated contact hypersensitivity reaction, supporting the hypothesis that LCs more likely promote T-cell activation.

In the dermis, antigen-presenting cell populations are far more complex. Dermal DCs (DDCs) are considered the skin counterpart of interstitial DCs found in the interstitium of solid organs. Although DDCs have long been defined as a homogeneous population based on the expression of the transglutaminase factor XIIIA (FXIIIA) [4], it is now clear that there is no single feature (morphology or localization) or marker that allows a correct distinction between DDCs and DMs. In analogy to other tissues, most of the markers used for the identification of cutaneous myeloid DCs and macrophages significantly overlap (Fig. 1). In the past 5 years, the usage of classical DDCs markers combined with antibodies to blood dendritic cell antigens (BDCA1-3) either on dermal single cell suspensions and on sections, significantly changed the scenario of skin DCs $[5,6,7 \cdot \bullet$, $8-14]$. In addition to DMs, it can be now possible to distinguish at least three major DDCs subsets in the dermis (Table 1). The most abundant DDCs subset is represented by CD1c + (BDCA-1) immature mDCs. These cells coexpress CD11c, CD209, and low levels of CD1a. They likely migrate to draining lymph nodes via CCR7 where they can potently stimulate $\mathrm{T}$ cells, although at lesser extent compared with mature DCs [12]. In addition to CD1c + DCs, reports from different groups indicated that $\mathrm{CD} 14+\mathrm{DCs}$ normally occur in the dermis; this DCs subset is more closely related to blood monocytes and in vitro derived DCs, as indicated by their transcriptomic profile [7••]. Finally, a third DCs subset is characterized by high expression of CD141 (BDCA-3). CD141 identify thrombomodulin, an integral membrane protein expressed on the surface of endothelial cells, blood monocytes, and circulating DCs that serves as a cofactor for thrombin. The occurrence of $\mathrm{CD} 141^{+}$DDCs was originally reported more than a decade ago by Cuzzi-Maya and colleagues [15]. Interestingly, the recent phenotypic (expression of XCR1, TLR3, CLEC9A, and CADM1) and functional analysis of CD141 $1^{\text {high }}$ DCs indicate that they are capable to efficiently cross-present antigens to T cells [14]. Recently, also SlanDCs, which were initially described as large population of circulating proinflammatory DCs, have been identified among resident
DDCs [16]. Although it is conceivable that circulating PDCs can occasionally home to normal skin and be detected by fluorescence-based in situ strategies, as previously reported $[12,17]$, an extensive analysis of formalin-fixed normal human skin sections performed in our laboratory indicates that BDCA2+ PDCs are not part of the resident skin DCs contingent (Fig. 1).

\section{Brief Overview of Human PDCS}

More detailed overview covering different areas of PDCs history and biology can be found elsewhere in the literature [18-20]. From the identification as "lymphoblasts" by Karl Lennert in 1958 [21], PDCs were given a number of different names [22, 23]; however, when in vitro data provided evidence that they represent a subset of DCs [24] and produce high amount of type I interferon $[25,26]$, a functional terminology has been adopted defining these cells either as to plasmacytoid dendritic cells or interferon-producing cells.

PDCs originate in the bone marrow from a dendritic cell progenitor common to PDCs and conventional "myeloid" DCs $[27,28]$. In the blood, they are defined by the HLADR +/CD11c-/lin-/CD123+/BDCA-2+ phenotype. In tissues, PDCs mainly reside in the peripheral lymph nodes and tonsils $[29,30]$ but also can be found in the thymic medulla, bone marrow, spleen (at the boundary between white and red pulp), and mucosa-associated lymphoid tissue. Although different reagents have used in the past, CD123 and BDCA2/CD303 represent the most specific and sensitive markers for PDCs [31 , 32]. It should be keep in mind, however, that CD123 can be detected with lower intensity on other cell types, such as endothelial cells [33], activated macrophages, and subsets of dendritic cells [31•]. BDCA-2/CD303 can be partially lost upon PDCs activation in inflammatory processes [32,34], but no other cells are known to express this antigen. Interestingly, PDCs express granzyme B but not perforin and TIA-1 $[35,36]$. PDCs show distinctive profile of pathogen recognition receptors, mainly expressing the endosome-associated Toll-like receptors (TLR)-7 and 9. Their engagement (viral RNA and DNA sequences) in PDCs leads to powerful type I interferon (I-IFN) secretion and differentiation to DCs [37-39]. The master mediator of I-IFN production occurring downstream of TLR-7/9 signaling is the transcription factor IRF7, whose constitutive expression by PDCs also may explain their robust production of this cytokine upon activation [40].

In addition to I-IFN, PDCs produce other cytokines, including tumor necrosis factor (TNF)- $\alpha$, IL- 6 , and CXCL8 $[41,42]$, and proinflammatory chemokines, such as CXCL9, CXCL10, CCL3, CCL4, and CCL5 [43], thus participating to the organization of a panoply of innate and 
Table 1 Dominant phenotype of DDC and DMs in human normal skin based

\begin{tabular}{|c|c|c|c|c|}
\hline Marker & $\begin{array}{l}\text { MФ } \\
\text { (IS/FC) }\end{array}$ & $\begin{array}{l}\mathrm{CD} 1 \mathrm{c}^{+} \mathrm{DC} \\
(\mathrm{IS} / \mathrm{FC})\end{array}$ & $\begin{array}{l}\text { CD141 }{ }^{\text {high }} \text { DC } \\
\text { (IS/FC) }\end{array}$ & $\begin{array}{l}\text { CD14 DC } \\
\text { (IS/FC) }\end{array}$ \\
\hline CD11c & [12] Negative / $[9,12]$ Positive $^{\mathrm{L}}$ & {$[11,13]$ Positive / [12]Positive ${ }^{\mathrm{H}}$} & $\begin{array}{c}\text { ND/ }[7 \cdot \bullet, 13] \\
\text { Positive }^{\mathrm{L} \text { to I }}\end{array}$ & ND/ [6]Positive \\
\hline CD1a & [9]Negative / [6]Negative & {$[11,13]$ Positive/ [6]Positive } & $\mathrm{ND} /[7 \bullet \bullet]$ Positive $^{\mathrm{L}}$ & $\mathrm{ND} /[5,8]$ Negative \\
\hline CD163 & {$[6,12]$ Positive / $[6,12] \mathrm{Positive}^{\mathrm{H}}$} & [12]Negative / [6]Negative & $\mathrm{ND} / \mathrm{ND}$ & $\mathrm{ND} /[6,16]$ Positive $^{\mathrm{L}}$ \\
\hline FXIIIa & [6]Positive / [12]Postive ${ }^{\mathrm{H}}$ & [12] Negative/[12]Positive ${ }^{\mathrm{L}}$ & $\mathrm{ND} / \mathrm{ND}$ & [11]Positive/ [6, 8]Positive \\
\hline CD68 & [9]Positive/ND & Positive [12]/ ND & $\mathrm{ND} / \mathrm{ND}$ & [5]Positive/ ND \\
\hline CD206 & {$[9,12]$ Positive/ ND } & [12]Positive /ND & $\mathrm{ND} / \mathrm{ND}$ & [5]Positive/ ND \\
\hline CD209 & {$[9,12]$ Positive/ ND } & {$[12,13]$ Positive/ ND } & ND/ ND & [5]Positive/ [8]Positive \\
\hline CD207 & [9]Negative/ ND & [12]Negative/ ND & $\mathrm{ND} /[7 \bullet \bullet]$ Negative & $\mathrm{ND} /[5,8]$ Negative \\
\hline $\mathrm{CD} 1 \mathrm{c}$ & [6]Negative/[12]Negative & [12]Positive/[12]Positive $\mathrm{e}^{\mathrm{H}}$ & $\mathrm{ND} /[7 \bullet \bullet]$ Positive & $\mathrm{ND} /[8]$ Negative or [6]Positive \\
\hline CD303 & [12]Negative/ ND & {$[12,13]$ Negative/ ND } & [13]Negative/ND & [13] Negative/ ND \\
\hline CD141 & $\mathrm{ND} / \mathrm{ND}$ & $\mathrm{ND} /[7 \cdot \bullet, 12]$ Positive $^{\mathrm{L}}$ & $\mathrm{ND} /[12]$ Positive $^{\mathrm{H}}$ & ND/ $[7 \bullet \bullet]$ Negative \\
\hline CD14 & [9]Positive/ [6]Positive & {$[11,13]$ Negative/ ND } & $\mathrm{ND} /[7 \cdot \bullet]$ Negative & [5]Positive/ [5]Positive $\mathrm{P}^{\mathrm{H}}$ \\
\hline
\end{tabular}

$I S$ in situ technique (immunohistochemistry and immunofluorescence); $F C$ flow cytometry; $L$ low; $I$ intermediate; $H$ high; $N D$ not done

adaptive immune responses [42]. I-IFN regulates many Tcell functions, including long-term T-cell survival and memory T-helper 1 polarization, CD8+ T-cell cytolytic activity, and interferon (IFN)- $\gamma$ production [39]. PDCs also potentiate NK cell-mediated cytotoxicity and IFN- $\gamma$ production, induce differentiation and maturation of myeloid DCs and, together with IL-6, cooperate in the differentiation of B lymphocytes into immunoglobulin-secreting plasma cells [44]. It has been shown that PDCs also can kill tumors and virus-infected cell lines, either by secreting TRAIL (TNFrelated apoptosis-inducing ligand) upon activation or indirectly by activating other cytotoxic cells via I-IFN [45, 46].

\section{Cutaneous Migration of PDCS to Inflamed Skin}

Details on the mechanisms guiding PDCs to human tissues have been extensively reviewed elsewhere by our group [19]. Although mostly absent in peripheral nonlymphoid tissue, blood PDCs can accumulate in inflamed tissues [18-20], particularly in the skin. This propensity might reflect the expression of skin homing molecules by PDCs. Circulating PDCs express multiple chemotactic receptors; however, only CXCR 4 and ChemR 23 are biologically active receptors in healthy donors $[19,47]$. Because CXCL12 is widely expressed in tissues, the CXCR4/CXCL12 axis might account for PDCs accumulation in many pathological conditions. Significantly CXCR3 ligands increase the chemotactic response of PDCs to CXCL12 [48, 49]. Recently, we have proposed chemerin and its cognate receptor, ChemR23, as a crucial chemotactic factor for human PDCs in different skin inflammatory disorders [50]. In the following sections, we will summarize data supporting the role of PDCs in the pathogenesis of some of the most relevant skin disorders. It is well established that PDCs are capable of organize the local immune response in inflamed tissues. In particular, they represent a relevant source of proinflammatory chemokines, including CCL3, CCL4, CCL5, CXCL9, and CXCL10, which can attract activated CD4+ and CD8+ T cells to sites of inflammation [19, 43].

\section{Autoimmune Inflammatory Dermatoses}

PDCs accumulate in some inflammatory dermatoses where they participate to the organization of the local immune responses [51]. The most characterized examples are lupus erythematosus (LE) [52] and psoriasis (PS) [53・•]. In LE and PS, cutaneous accumulation of PDCs is dependent on the local activation of the chemerin/ChemR23 axis [32, 50, $54 \cdot \bullet$. In particular, chemerin is strongly produced in the inflamed skin by keratinocytes, dermal vessels, and fibroblasts, whereas skin-infiltrating PDCs express ChemR23. In this context, it should be considered that the release of proteolytic enzymes, such as cathepsin G, elastase, and tryptase by activated neutrophils and mast cells is instrumental to convert inactive prochemerin to functional chemerin. Remarkably, the kinetics and distribution of cutaneous PDCs infiltration as well as mechanisms of PDCs activation are different in these two conditions.

In LE skin lesions, PDCs generally persist during the entire spectrum of the disease [32]. By studying the immune cell repertoire in a large cohort of LE skin biopsies, we could confirm cutaneous infiltration of BDCA2 $2^{+}$PDCs as 
hallmark of LE. However, PDCs were more frequently observed and numerous in cutaneous LE compared with systemic LE, suggesting a broader tissue distribution of this cells in the systemic form of the disease. Remarkably, the distribution of cutaneous PDCs showed two distinct patterns. More commonly, PDCs were observed within perivascular inflammatory nodules in the dermis, associated with mature DCs, whereas a second component was observed along the dermal-epithelial junction (junctional PDCs; Fig. 2). A large body of preclinical models and clinical evidences (reviewed in [52]) has suggested a fundamental role of PDCs in the pathogenesis of LE, mainly via IFN-I production. Accordingly, we could document that type I IFN-inducible gene MxA is abundantly produced in LE skin by keratinocytes, dermal inflammatory cells and vessels. In LE, IFN-I is induced in response to nucleic acidcontaining immune complexes internalized through Fc $\gamma$ RIImediated endocytosis. Immune complexes reach the endosomal compartment and activate TLR9. PDCs activation is further prolonged by the HMGB1-RAGE interaction [55 ${ }^{\bullet}$. HMGB1, a nuclear DNA-binding protein, is passively released from damaged (i.e., necrotic) cells or secreted by monocyte-derived cells including macrophages and myeloid DCs exposed to inflammatory cytokines [56, 57]. Significantly, both keratinocytes and dermal mononuclear inflammatory cells in the skin samples from patients with LE showed strong induction of HMGB1 [58]. HMGB1 also is secreted by PDCs stimulated with $\mathrm{CpG}$ ODN and might regulate the production of IFN-I in an autocrine fashion [59]. All of these findings suggest that HMGB1 may contribute significantly to the persistent local activation of PDCs in LE, where immune complexes deposition, tissue damage, and recruitment of myeloid DCs and macrophages co-occur. LE PDCs also express the cytotoxic molecule granzyme B and, remarkably, the junctional PDCs contingent is found in association with perforin-expressing cytotoxic $\mathrm{T}$ cells in areas of severe epithelial damage. These findings suggest a potential contribution of junctional PDCs to the generation epithelial cell death not only as adjuvant (via IFN-I) but also as effector cells via secretion of cytotoxic molecules. Granzyme B production by PDCs requires IL-3 and is enhanced by the immunosuppressive cytokine
IL-10 [60]. However, it remains to be clarified which proinflammatory stimuli in LE PDCs can execute the granzyme B effector program. Cytotoxic damage is a major pathological event in the "interface" dermatitis found in LE, and similar changes, albeit to a lesser extent, can be observed in lichen planus, where PDCs colocalize at the dermoepidermal junction with NK cells [61].

Compared with LE, the role of PDCs and INF-I in the pathogenesis of PS has been envisaged only recently [62]. Relevant to the pathogenesis of PS is the combination of events involving both keratinocytes and immune cells [63]. It is widely accepted that a skin immune reaction to still unknown antigens is central to PS. Th1- or Th17-polarized infiltrating T-cells are skewed to produce IFN- $\gamma$, TNF- $\alpha$, IL-17, and IL-22. Also, innate immune cells, including neutrophils, monocytes, macrophages, and natural killer T cells, have been implicated in the pathogenesis of PS. Infiltration of IFN-I producing PDCs in PS has been recently demonstrated by different groups and appear to be predominantly found in early phases of the disease (Fig. 2) [53••, $54 \bullet \bullet$. Significantly, xenograft models indicate that blocking of IFN-I production by PDCs or IFN-I signalling inhibits expansion of pathogenic T-cells and PS development [53••]. However, based on the kinetics of the PDCs distribution in human PS skin [53••, 54••] (presence only in early active plaque but not in the chronic phase), it seems that only transient production of IFN-I is required for PS to develop. PDCs activation in PS is linked to the cationic endogenous antimicrobial peptide LL37. The bioactive form of LL37-a member of the cathelicidins family produced by keratinocytes and neutrophils - results from cleavage of the hCAP18 propeptide by serine proteases [64]. LL37 is able to bind and convert extracellular self-DNA fragments into aggregated particles that are resistant to DNase. These complexes enter PDCs by lipid-raft mediated endocytosis and once delivered to the early endocytic compartments potently trigger TLR9-dependent IFN response [65•, 66•]. Significantly, binding of HMGB1/RAGE to these complexes might prolong their association with TLR9. It has been recently demonstrated that also self-RNA forms complexes with LL37 [65 ] capable to induce TLR7 activation in PDCs leading to IFN-I secretion. In PS lesions [67] LL37 is
Fig. 2 PDCs in LE and PS. Formalin-fixed human skin sections are from LE (left) and PS (right) patients and stained for anti-CD303 (revealed by $\mathrm{DAB}$, brown). Sections are counterstained with Meyer's hematoxylin. Magnification $100 \times$
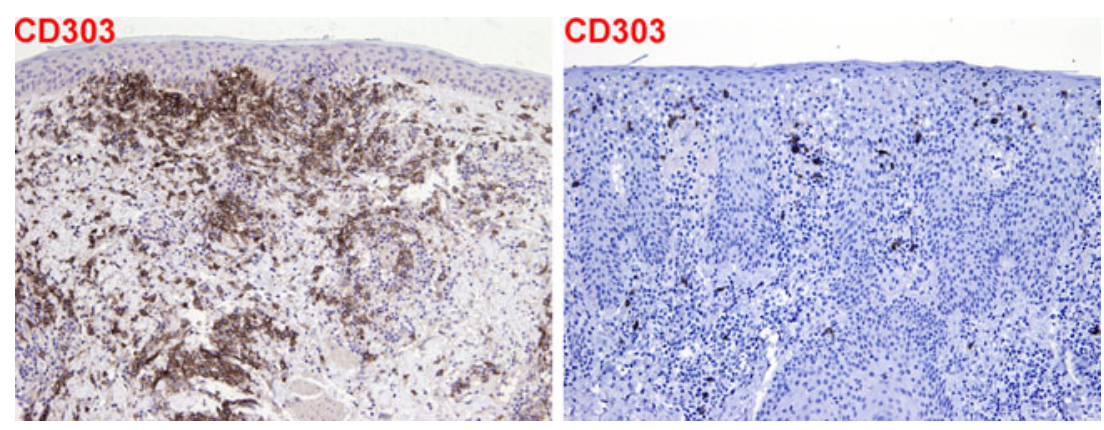
strongly induced in keratinocytes throughout the development of the lesion. An additional source of LL37 that might sustain PDCs activation is represented by neutrophils that might represent a significant fraction of the immune cell repertoire in PS. A very recent finding by Tohyama et al. suggests a new connection between IFN-I and PS by showing that this cytokine specifically up-regulates the expression of IL-22R on keratinocytes [68 $]$. This data strongly support the hypothesis that PDCS cross-talk with IL-22 producing $\mathrm{T}$ cells might contribute to regulate epidermal remodeling in PS [69].

\section{Role of PDCS in Immune Surveillance to Skin Tropic Viruses}

PDCs can detect viral RNA and DNA through TLR7 and TLR9 and secrete large amounts of IFN-I in response to a variety of viruses in vitro and in vivo [37]. It is well established that IFN-I confers resistance to viruses by different mechanisms (reviewed by [39]) However, PDCs may contribute to antiviral defence through additional mechanisms including direct- or cross-presentation of viral antigens to $\mathrm{T}$ cells $[70,71]$ and $\mathrm{T}$ helper 1 (Th1) cell polarization of $\mathrm{CD} 4+\mathrm{T}$ cells by secreting $\mathrm{IL}-12$ [72, 73]. In addition, PDCs can directly exert effector function and kill virus-infected cells through FasL- and TNF-related apoptosis inducing ligand (TRAIL)-dependent mechanisms $[45,74]$. When tested in vivo in the optimal experimental system, specific PDCs depletion impacts on the amplitude of virus-specific NK cell or CD8+ Tcell responses in a fashion that is dependent on the infecting agent and viral burden [75••].

In humans, the role of PDCs in viral infections has been suggested in the setting of HIV and hepatitis [76-78]. In the human skin, accumulation of PDCs has been reported only in acute varicella infection [79] and in HPV-associated Verruca vulgaris [80]. Our group recently characterized the local immune cell repertoire in Molluscum contagiosum virus (MCV) infection of the skin [31•]. In immune competent host MCV, induces self-limiting tumor-like cutaneous lesions that can undergo spontaneous regression preceded by local inflammation. The cellular mechanisms underling this event are still incompletely understood. In our study, we analysed 36 cases of MCV-induced skin lesions. By histology and immunohistochemistry, we identified highly immunogenic MCV-induced lesions showing a dense and composite immune reaction associated with cell death in keratinocytes. Immune cell infiltration consisted of numerous cytotoxic $\mathrm{T}$ cells admixed with natural killer cells and IFN-I producing PDCs. Among IFN-I target cells infiltrating regressing MCV lesions we could identify a cell population resembling the so-called "IFN-DCs" characterized by the expression of CD123, CD11c, CD16, and CD14. IFN-DCs represent recently identified DCs populations that can be generated in vitro by type I IFN conditioning of peripheral blood monocytes [81-86]. In vitro generated IFN-DCs are effective in taking up antigens and produce several chemokines and cytokines that can induce Th1 and Th17 polarization $\left[87,88^{\bullet}\right]$. In addition, IFN-DCs also might exert direct effector function via TRAIL and Granzyme B [89]. These and additional series of data [90 ${ }^{\bullet}$ have suggested clearly that IFN-DCs might represent promising adjuvants for cancer immunotherapy. In our study, we showed that MCV-infiltrating IFN-DCs strongly reacted to IFN-I inducible genes. In addition, these cells were strategically located in close proximity to apoptotic keratinocytes, suggesting their direct involvement in the rejection process. It has been reported that IFN-DCs can contribute in different ways to the local immune surveillance to viruses. IFN-DCs can cross-present viral antigen to $\mathrm{CD} 8^{+} \mathrm{T}$ cells, increase the immunogenicity of infected cells by producing IFNs or exert effector functions through GrB and TRAIL [84, 91]. In our study, we could document GrB and TRAIL expression by MCV-associated IFN-DCs and, accordingly, our in vitro generated IFN-DCs showed a strong induction of TRAIL and FasL. It is still unclear how PDCs get activated in MCV-lesions [92]. In addition to a direct sensing of MCV through TLR9, PDCs can be activated by contact with MCV-infected keratinocytes. A third hypothesis suggests PDCs might sense self-DNA or self-RNA complexed to LL-37 secreted by keratinocytes and surrounding polymorphonuclear cells. To our view, PDCs and IFN-DCs might significantly also contribute as effector cells to clear MCV from the skin of infected patients. It is highly likely that IFN-DCs can be generated in other clinical settings, including autoimmune disorders, such as LE, PS, and lichen planus [87]. In the latter cases, it will be of worth to establish how IFN-DCs impact skin pathology.

\section{Blastic Plasmacytoid Dendritic Cell Neoplasm}

Tumoral proliferations of plasmacytoid dendritic cells (PDCs) are rare hematological neoplasms, which may occur in two clinically and pathologically different forms, respectively derived from mature and immature PDCs. The former mainly involves lymph nodes and bone marrow and is invariably associated with a clinically dominant myeloid neoplasm [93], whereas blastic plasmacytoid dendritic cell neoplasm (BPDCN) derives from immature precursors of PDCs and shows a distinctive cutaneous tropism, with rapid and progressive systemic extension [94]. The striking tendency of BPDCN tumor cells to localize to the skin has been related to the expression of antigens that favour skin migration, such as CLA and CD56 [95], as well as to the local 
production of ligands of chemokines expressed by tumor cells (CXCR3, CXCR4, CCR6, CCR7) [96]. BPDCN occur in approximately $75 \%$ of cases in males and the median age at diagnosis is 66.0 years, but $13 \%$ of cases have been reported in individuals younger than age 20 years. There are currently no clues to the etiology of BPDCN, and Epstein-Barr virus (EBV) as well as other viruses (HIV, HCV, HHV6, HHV8, CMV, and HTLV-1 or 2) are generally negative [97•].

There are no specific karyotypic abnormalities in BPDCN. BPDCN belongs to the wide spectrum of myeloid neoplasms that display TET2 mutations [98]. Nevertheless, the genetic as well as the gene expression profile [99] in BPDCN is fundamentally distinct from that in myeloid leukemias; in particular, JAK2 or NPM mutations are regularly lacking $[98,100]$, whereas tandem duplication of FLT3 (TD-FLT3) are very rarely observed [97•]. Overall, the complex genetic anomalies encountered in BPDCN have been shown to result in losses of factors involved in the G1/S transition pathway and on the cell-cycle checkpoint controlling proteins (e.g., $C D K N 2 A, C D K N 2 B$ genes, $R B 1$, LATS2, TP53, CDKN1B, and ETV6) [101, 102] that could represent a crucial and early oncogenic event in BPDCN, providing a basis for the phenomenon of chemoresistance that frequently develops, despite an initial favorable response to chemotherapy.

The overall health of patients at presentation is generally good, and the main reason for seeking medical advice is cutaneous lesions. The interval between the first symptoms and the diagnosis ranges from 1 to 18 months [103]. The clinical presentation of skin lesions is extremely heterogeneous: they can be solitary, grouped in one area, or generalized, and appear as flat maculae, plaques or nodules; the size ranges from few millimeters to several centimeters, and the appearance may be erythematous, hyperpigmented, reddish, bluish, purpuric, erosive, or even necrotic [104, 105]. BPDCN is characterized by a rather monomorphous and dense infiltrate composed of cells with blastic features resembling myeloblasts or lymphoblasts [94, 97•]. Diagnosis of BPDCN inevitably relays on immunophenotyping: the expression of CD4 and CD56 (the latter representing an antigen not expressed on normal PDCs) in the absence of lineage specific markers for myelomonocytic, NK cells, $\mathrm{T}$ cells, or B cells, has defined the majority of cases of BPDCN. BPDCN diagnosis has been greatly improved with the development of more specific PDCs-associated markers, such as CD123, TCL1, BDCA-2/CD303, CD2AP [97], and BAD-LAMP BPDCN [106]. Due to their blastic nature, aberrant expression of antigens related to immaturity like TdT and CD117, but not CD34, can be observed.

BPDCN may show a deceptively indolent clinical presentation, with initial resolution of symptoms in most cases using a variety of intensive chemotherapy regimens or steroids, but the course is almost invariably aggressive, with early relapses and rapid extracutaneous dissemination, with or without overt leukemia. The median survival varies from 10 to 16.7 months. At present, there is no consensus for optimal treatment of BPDCN, but sustained clinical remission or cure has been reported in patients who received acute leukemia chemotherapy regimens and allogeneic stem cell transplantation in first complete remission [103, 107-109]. Although allogeneic stem cell transplantation is now advocated for BPDCN treatment in adults, its role in pediatric cases is unclear, and it has been recommended that treatment of children with BPDCN would include ALL-type therapy with central nervous system prophylaxis, reserving SCT for second complete remission or for cases in which initial treatment does not induce a rapid or complete remission [110].

\section{Conclusions}

PDC are absent in healthy skin. However, a series of preclinical and clinical observations have confirmed that they are recruited to inflamed skin in different disorders, mainly via Chemerin/ChemR23 axis. Although it is still largely unknown how PDCs interact with other resident immune cells, it is now clear that activated PDC sustain autoimmunity in predisposed individuals but might also eradicate cutaneous-tropic viruses. In skin autoimmunity, PDCs amplify and polarize local adaptive immune responses via production of IFN-I and exert direct effector functions at the dermoepidermal interface. This set of valuable information is forming the groundwork for targeting cutaneous PDC infiltration and activation in these disorders.

Acknowledgments The authors are grateful to past and present people in the lab who have contributed to the characterization of plasmacytoid dendritic cells and to Federica Calzetti (University of Verona) for criticisms and comments. WV is supported by PRIN (Ministero dell'Istruzione dell'Università e della Ricerca, 2009) and AIRC (Associazione Italiana per la ricerca sul cancro, 2010, IG 11924).

Disclosure The authors reported no potential conflicts of interest relevant to this article.

\section{References}

Papers of particular interest, published recently, have been highlighted as:

- Of importance

•• Of major importance

1. Kaplan DH. In vivo function of Langerhans cells and dermal dendritic cells. Trends Immunol. 2010;31(12):446-51. 
2. Romani N, Brunner PM, Stingl G. Changing views of the role of Langerhans cells. J Investig Dermatol. 2012;132(3 Pt 2):872-81.

3. Wang Y, Szretter KJ, Vermi W, et al. IL-34 is a tissue-restricted ligand of CSF1R required for the development of Langerhans cells and microglia. Nat Immunol. 2012;13(8):753-60.

4. Cerio R, Griffiths CE, Cooper KD, et al. Characterization of factor XIIIa positive dermal dendritic cells in normal and inflamed skin. Br J Dermatol. 1989;121(4):421-31.

5. Angel CE, Lala A, Chen CJ, et al. CD14+ antigen-presenting cells in human dermis are less mature than their CD1a + counterparts. Int Immunol. 2007;19(11):1271-9.

6. Haniffa M, Ginhoux F, Wang XN, et al. Differential rates of replacement of human dermal dendritic cells and macrophages during hematopoietic stem cell transplantation. J Exp Med. 2009;206(2):371-85.

7. •• Haniffa M, Shin A, Bigley V, et al. Human tissues contain CD141hi cross-presenting dendritic cells with functional homology to mouse CD103+ nonlymphoid dendritic cells. Immunity. 2012;37 (1):60-73. This article provides a detailed phenotypic and functional analysis of dendritic cells in the human dermis.

8. Klechevsky E, Morita R, Liu M, et al. Functional specializations of human epidermal Langerhans cells and CD14+ dermal dendritic cells. Immunity. 2008;29(3):497-510.

9. Ochoa MT, Loncaric A, Krutzik SR, et al. "Dermal dendritic cells" comprise two distinct populations: CD1+ dendritic cells and CD209 + macrophages. J Investig Dermatol. 2008;128(9):2225-31.

10. Turville SG, Cameron PU, Handley A, et al. Diversity of receptors binding HIV on dendritic cell subsets. Nat Immunol. 2002;3 (10): $975-83$.

11. Ueno H, Schmitt N, Palucka AK, et al. Dendritic cells and humoral immunity in humans. Immunol Cell Biol. 2010;88 (4):376-80.

12. Zaba LC, Fuentes-Duculan J, Steinman RM, et al. Normal human dermis contains distinct populations of CD11c + BDCA-1+ dendritic cells and CD163 + FXIIIA + macrophages. J Clin Invest. 2007;117(9):2517-25.

13. Zaba LC, Krueger JG, Lowes MA. Resident and "inflammatory" dendritic cells in human skin. J Investig Dermatol. 2009;129 (2):302-8.

14. Dalod M. Professional cross-presenting CD8alpha-type CD141(hi) dendritic cells: we have got you in our skin! Immunity. 2012;37 (1):3-5.

15. Cuzzi-Maya T, Sidbury R, Epstein WL, et al. Thrombomodulin expression on dermal cells in normal and psoriatic skin. Arch Dermatol Res. 1998;290(5):233-9.

16. Gunther C, Starke J, Zimmermann N, et al. Human 6-sulfo LacNAc (slan) dendritic cells are a major population of dermal dendritic cells in steady state and inflammation. Clin Exp Dermatol. 2012;37(2):169-76.

17. Ebner S, Ehammer Z, Holzmann S, et al. Expression of C-type lectin receptors by subsets of dendritic cells in human skin. Int Immunol. 2004;16(6):877-87.

18. Colonna M, Trinchieri G, Liu YJ. Plasmacytoid dendritic cells in immunity. Nat Immunol. 2004;5(12):1219-26.

19. Sozzani S, Vermi W, Del Prete A, et al. Trafficking properties of plasmacytoid dendritic cells in health and disease. Trends Immunol. 2010;31(7):270-7.

20. Facchetti F, Vermi W, Mason D, et al. The plasmacytoid monocyte/ interferon producing cells. Virchows Arch. 2003;443(6):703-17.

21. Lennert K, Remmele W. Karyometric research on lymph node cells in man. I. Germinoblasts, lymphoblasts \& lymphocytes. Acta Haematol. 1958;19(2):99-113.

22. Muller-Hermelink HK, Stein H, Steinmann G, et al. Malignant lymphoma of plasmacytoid T-cells. Morphologic and immunologic studies characterizing a special type of T-cell. Am J Surg Pathol. 1983;7(8):849-62.
23. Facchetti F, de Wolf-Peeters C, Mason DY, et al. Plasmacytoid T cells. Immunohistochemical evidence for their monocyte/macrophage origin. Am J Pathol. 1988;133(1):15-21.

24. Grouard G, Rissoan MC, Filgueira L, et al. The enigmatic plasmacytoid T cells develop into dendritic cells with interleukin (IL)3 and CD40-ligand. J Exp Med. 1997;185(6):1101-11.

25. Cella M, Jarrossay D, Facchetti F, et al. Plasmacytoid monocytes migrate to inflamed lymph nodes and produce large amounts of type I interferon. Nat Med. 1999;5(8):919-23.

26. Siegal FP, Kadowaki N, Shodell M, et al. The nature of the principal type 1 interferon-producing cells in human blood. Science. 1999;284(5421):1835-7.

27. Liu K, Victora GD, Schwickert TA, et al. In vivo analysis of dendritic cell development and homeostasis. Science. 2009;324 (5925):392-7.

28. Naik SH, Sathe P, Park HY, et al. Development of plasmacytoid and conventional dendritic cell subtypes from single precursor cells derived in vitro and in vivo. Nat Immunol. 2007;8(11):1217-26.

29. Facchetti F, De Wolf-Peeters C, van den Oord JJ, et al. Plasmacytoid T cells: a cell population normally present in the reactive lymph node. An immunohistochemical and electronmicroscopic study. Hum Pathol. 1988;19(9):1085-92.

30. Jegalian AG, Facchetti F, Jaffe ES. Plasmacytoid dendritic cells: physiologic roles and pathologic states. Adv Anat Pathol. 2009;16(6):392-404.

31. • Vermi W, Fisogni S, Salogni L, et al. Spontaneous regression of highly immunogenic Molluscum contagiosum virus (MCV)induced skin lesions is associated with plasmacytoid dendritic cells and IFN-DC infiltration. J Investig Dermatol. 2011;131 (2):426-34. This article identifies $P D C$ and IFN-DC in regressing $M C V$-induced infections of the skin.

32. Vermi W, Lonardi S, Morassi M, et al. Cutaneous distribution of plasmacytoid dendritic cells in lupus erythematosus. Selective tropism at the site of epithelial apoptotic damage. Immunobiology. 2009;214(9-10):877-86.

33. Olweus J, BitMansour A, Warnke R, et al. Dendritic cell ontogeny: a human dendritic cell lineage of myeloid origin. Proc Natl Acad Sci U S A. 1997;94(23):12551-6.

34. Dzionek A, Sohma Y, Nagafune J, et al. BDCA-2, a novel plasmacytoid dendritic cell-specific type II C-type lectin, mediates antigen capture and is a potent inhibitor of interferon alpha/ beta induction. J Exp Med. 2001;194(12):1823-34.

35. Rissoan MC, Duhen T, Bridon JM, et al. Subtractive hybridization reveals the expression of immunoglobulin-like transcript 7 , Eph-B1, granzyme B, and 3 novel transcripts in human plasmacytoid dendritic cells. Blood. 2002;100(9):3295-303.

36. Facchetti F, Vermi W, Santoro A, et al. Neoplasms derived from plasmacytoid monocytes/interferon-producing cells: variability of CD56 and granzyme B expression. Am J Surg Pathol. 2003;27 (11):1489-92. author reply 1492-3.

37. Gilliet M, Cao W, Liu YJ. Plasmacytoid dendritic cells: sensing nucleic acids in viral infection and autoimmune diseases. Nat Rev Immunol. 2008;8(8):594-606.

38. Ito T, Wang YH, Liu YJ. Plasmacytoid dendritic cell precursors/ type I interferon-producing cells sense viral infection by Toll-like receptor (TLR) 7 and TLR9. Springer Semin Immunopathol. 2005;26(3):221-9.

39. Swiecki M, Colonna M. Unraveling the functions of plasmacytoid dendritic cells during viral infections, autoimmunity, and tolerance. Immunol Rev. 2010;234(1):142-62.

40. Cao W. Molecular characterization of human plasmacytoid dendritic cells. J Clin Immunol. 2009;29(3):257-64.

41. Decalf J, Fernandes S, Longman R, et al. Plasmacytoid dendritic cells initiate a complex chemokine and cytokine network and are a viable drug target in chronic $\mathrm{HCV}$ patients. J Exp Med. 2007;204(10):2423-37. 
42. Liu YJ. IPC: professional type 1 interferon-producing cells and plasmacytoid dendritic cell precursors. Annu Rev Immunol. 2005;23:275-306.

43. Penna G, Vulcano M, Roncari A, et al. Cutting edge: differential chemokine production by myeloid and plasmacytoid dendritic cells. J Immunol. 2002;169(12):6673-6.

44. Jego G, Pascual V, Palucka AK, et al. Dendritic cells control B cell growth and differentiation. Curr Dir Autoimmun. 2005;8:124-39.

45. Chaperot L, Blum A, Manches O, et al. Virus or TLR agonists induce TRAIL-mediated cytotoxic activity of plasmacytoid dendritic cells. J Immunol. 2006;176(1):248-55.

46. Stary G, Bangert C, Tauber M, et al. Tumoricidal activity of TLR7/8-activated inflammatory dendritic cells. J Exp Med. 2007;204(6):1441-51.

47. Penna G, Sozzani S, Adorini L. Cutting edge: selective usage of chemokine receptors by plasmacytoid dendritic cells. J Immunol. 2001;167(4):1862-6.

48. Krug A, Uppaluri R, Facchetti F, et al. IFN-producing cells respond to CXCR3 ligands in the presence of CXCL12 and secrete inflammatory chemokines upon activation. J Immunol. 2002;169(11):6079-83.

49. Vanbervliet B, Bendriss-Vermare N, Massacrier C, et al. The inducible CXCR3 ligands control plasmacytoid dendritic cell responsiveness to the constitutive chemokine stromal cellderived factor 1 (SDF-1)/CXCL12. J Exp Med. 2003;198 (5):823-30.

50. Vermi W, Riboldi E, Wittamer V, et al. Role of ChemR23 in directing the migration of myeloid and plasmacytoid dendritic cells to lymphoid organs and inflamed skin. J Exp Med. 2005;201 (4):509-15.

51. Meller S, Gilliet M, Homey B. Chemokines in the pathogenesis of lichenoid tissue reactions. J Investig Dermatol. 2009;129(2):315-9.

52. Banchereau J, Pascual V. Type I interferon in systemic lupus erythematosus and other autoimmune diseases. Immunity. 2006;25(3):383-92.

53. • Nestle FO, Conrad C, Tun-Kyi A, et al. Plasmacytoid predendritic cells initiate psoriasis through interferon-alpha production. J Exp Med. 2005;202(1):135-43. This article establishes the role of PDC in initiating psoriasis.

54. •- Albanesi C, Scarponi C, Pallotta S, et al. Chemerin expression marks early psoriatic skin lesions and correlates with plasmacytoid dendritic cell recruitment. J Exp Med. 2009;206(1):249-58. This article describes a role for the chemerin/ChemR23 axis in recruiting PDC in psoriatic skin lesions.

55. • Tian J, Avalos AM, Mao SY, et al. Toll-like receptor 9-dependent activation by DNA-containing immune complexes is mediated by HMGB1 and RAGE. Nat Immunol. 2007;8(5):487-96. This article demonstrates a mechanism by which HMGB1 and RAGE activate plasmacytoid dendritic in response to DNA.

56. Scaffidi P, Misteli T, Bianchi ME. Release of chromatin protein HMGB1 by necrotic cells triggers inflammation. Nature. 2002;418(6894):191-5.

57. Wang H, Bloom O, Zhang M, et al. HMG-1 as a late mediator of endotoxin lethality in mice. Science. 1999;285(5425):248 51.

58. Popovic K, Ek M, Espinosa A, et al. Increased expression of the novel proinflammatory cytokine high mobility group box chromosomal protein 1 in skin lesions of patients with lupus erythematosus. Arthritis Rheum. 2005;52(11):3639-45.

59. Dumitriu IE, Baruah P, Bianchi ME, et al. Requirement of HMGB1 and RAGE for the maturation of human plasmacytoid dendritic cells. Eur J Immunol. 2005;35(7):2184-90.

60. Jahrsdorfer B, Vollmer A, Blackwell SE, et al. Granzyme B produced by human plasmacytoid dendritic cells suppresses Tcell expansion. Blood. 2010;115(6):1156-65.
61. Parolini S, Santoro A, Marcenaro E, et al. The role of chemerin in the colocalization of $\mathrm{NK}$ and dendritic cell subsets into inflamed tissues. Blood. 2007;109(9):3625-32.

62. Albanesi C, Scarponi C, Bosisio D, et al. Immune functions and recruitment of plasmacytoid dendritic cells in psoriasis. Autoimmunity. 2010;43(3):215-9.

63. Lowes MA, Bowcock AM, Krueger JG. Pathogenesis and therapy of psoriasis. Nature. 2007;445(7130):866-73.

64. Zanetti M. The role of cathelicidins in the innate host defenses of mammals. Curr Issues Mol Biol. 2005;7(2):179-96.

65. - Ganguly D, Chamilos G, Lande R, et al. Self-RNAantimicrobial peptide complexes activate human dendritic cells through TLR7 and TLR8. J Exp Med. 2009;206(9):1983-94. This article demonstrates how LL37 converts self-RNA into a trigger of TLR7 and TLR8 in human dendritic cells.

66. • Lande R, Gregorio J, Facchinetti V, et al. Plasmacytoid dendritic cells sense self-DNA coupled with antimicrobial peptide. Nature. 2007;449(7162):564-9. This article demonstrates that LL37 converts self-DNA into a potent trigger of interferon production by $P D C$.

67. Frohm M, Agerberth B, Ahangari G, et al. The expression of the gene coding for the antibacterial peptide LL-37 is induced in human keratinocytes during inflammatory disorders. J Biol Chem. 1997;272(24):15258-63.

68. - Tohyama M, Yang L, Hanakawa Y, et al. IFN-alpha enhances IL-22 receptor expression in keratinocytes: a possible role in the development of psoriasis. J Investig Dermatol. 2012;132 (7):1933-5. This article demonstrate that IFN-I specifically upregulates the expression of $I L-22$ receptor on keratinocytes supporting the hypothesis that PDC might cross-talk with IL-22 producing T-cells in psoriasis.

69. Conrad C, Gilliet M. Type I IFNs at the interface between cutaneous immunity and epidermal remodeling. J Investig Dermatol. 2012;132(7):1759-62.

70. Villadangos JA, Young L. Antigen-presentation properties of plasmacytoid dendritic cells. Immunity. 2008;29(3):352-61.

71. Young LJ, Wilson NS, Schnorrer P, et al. Differential MHC class II synthesis and ubiquitination confers distinct antigen-presenting properties on conventional and plasmacytoid dendritic cells. Nat Immunol. 2008;9(11):1244-52.

72. Asselin-Paturel C, Boonstra A, Dalod M, et al. Mouse type I IFNproducing cells are immature APCs with plasmacytoid morphology. Nat Immunol. 2001;2(12):1144-50.

73. Cella M, Facchetti F, Lanzavecchia A, et al. Plasmacytoid dendritic cells activated by influenza virus and CD40L drive a potent Th1 polarization. Nat Immunol. 2000;1(4):305-10.

74. Hardy AW, Graham DR, Shearer GM, et al. HIV turns plasmacytoid dendritic cells (pDC) into TRAIL-expressing killer pDC and down-regulates HIV coreceptors by Toll-like receptor 7induced IFN-alpha. Proc Natl Acad Sci U S A. 2007;104 (44):17453-8.

75. • Swiecki M, Gilfillan S, Vermi W, et al. Plasmacytoid dendritic cell ablation impacts early interferon responses and antiviral NK and CD8(+) T cell accrual. Immunity. 2010;33(6):955-66. By using a diphtheria toxin receptor transgenic mice that selectively deplete PDC, this article clarify the PDC requirement during viral infections.

76. Donaghy H, Pozniak A, Gazzard B, et al. Loss of blood CD11c $(+)$ myeloid and CD11c(-) plasmacytoid dendritic cells in patients with HIV-1 infection correlates with HIV-1 RNA virus load. Blood. 2001;98(8):2574-6.

77. Duan XZ, Wang M, Li HW, et al. Decreased frequency and function of circulating plasmocytoid dendritic cells (pDC) in hepatitis B virus infected humans. J Clin Immunol. 2004;24 (6):637-46.

78. Kanto T, Inoue M, Miyatake H, et al. Reduced numbers and impaired ability of myeloid and plasmacytoid dendritic cells to 
polarize $\mathrm{T}$ helper cells in chronic hepatitis $\mathrm{C}$ virus infection. $\mathrm{J}$ Infect Dis. 2004;190(11):1919-26.

79. Gerlini G, Mariotti G, Bianchi B, et al. Massive recruitment of type I interferon producing plasmacytoid dendritic cells in varicella skin lesions. J Investig Dermatol. 2006;126(2):507-9.

80. Tassone L, Moratto D, Vermi W, et al. Defect of plasmacytoid dendritic cells in warts, hypogammaglobulinemia, infections, myelokathexis (WHIM) syndrome patients. Blood. 2010;116 (23):4870-3.

81. Santini SM, Lapenta C, Logozzi M, et al. Type I interferon as a powerful adjuvant for monocyte-derived dendritic cell development and activity in vitro and in Hu-PBL-SCID mice. J Exp Med. 2000;191(10):1777-88.

82. Santini SM, Di Pucchio T, Lapenta C, et al. A new type I IFN-mediated pathway for the rapid differentiation of monocytes into highly active dendritic cells. Stem Cells. 2003;21 (3):357-62.

83. Santini SM, Lapenta C, Belardelli F. Type I interferons as regulators of the differentiation/activation of human dendritic cells: methods for the evaluation of IFN-induced effects. Methods Mol Med. 2005;116:167-81.

84. Santini SM, Lapenta C, Santodonato L, et al. IFN-alpha in the generation of dendritic cells for cancer immunotherapy. Handb Exp Pharmacol. 2009;188:295-317.

85. Montoya M, Schiavoni G, Mattei F, et al. Type I interferons produced by dendritic cells promote their phenotypic and functional activation. Blood. 2002;99(9):3263-71.

86. Ferrantini M, Capone I, Belardelli F. Dendritic cells and cytokines in immune rejection of cancer. Cytokine Growth Factor Rev. 2008;19(1):93-107.

87. Farkas A, Kemeny L. Interferon-alpha in the generation of monocyte-derived dendritic cells: recent advances and implications for dermatology. Br J Dermatol. 2011.

88. - Santini SM, Lapenta C, Donati S, et al. Interferon-alphaconditioned human monocytes combine a Th1-orienting attitude with the induction of autologous Th17 responses: role of IL-23 and IL-12. PLoS One. 2011;6(2):e17364. This article demonstrates that IFN-DC induce expansion of both Th1 and Th17 cell populations.

89. Korthals M, Safaian N, Kronenwett R, et al. Monocyte derived dendritic cells generated by IFN-alpha acquire mature dendritic and natural killer cell properties as shown by gene expression analysis. J Transl Med. 2007;5:46.

90. • Moschella F, Proietti E, Capone I, et al. Combination strategies for enhancing the efficacy of immunotherapy in cancer patients. Ann N Y Acad Sci. 2010;1194:169-78. This article reviews the role of IFN-DC in cancer immune surveillance and suggest their potential application in anticancer treatment.

91. Lapenta C, Santini SM, Spada M, et al. IFN-alpha-conditioned dendritic cells are highly efficient in inducing cross-priming CD8 $(+) \mathrm{T}$ cells against exogenous viral antigens. Eur J Immunol. 2006;36(8):2046-60.

92. Swiecki M, Colonna M. Disparate antiviral responses in Molluscum contagiosum virus-induced skin lesions. J Investig Dermatol. 2011;131(2):288-90.

93. Vermi W, Facchetti F, Rosati S, et al. Nodal and extranodal tumor-forming accumulation of plasmacytoid monocytes/ interferon-producing cells associated with myeloid disorders. Am J Surg Pathol. 2004;28(5):585-95.

94. Facchetti F, Jones DM, Petrella T. Blastic plasmacytoid dendritic cells neoplasm. In: Swerdlow SH, Campo E, Harris NL, Jaffe ES,
Pileri SA, Stein H, Thiele J, Vardiman JW, editors. WHO classification of tumours of haematopoietic and lymphoid tissues. Lyon: International Agency for Research on Cancer; 2008. p. 145-7.

95. Weaver J, Hsi ED. CD4+/CD56+ hematodermic neoplasm (blastic NK-cell lymphoma). J Cutan Pathol. 2008;35(10):975-7.

96. Bendriss-Vermare N, Chaperot L, Peoc'h M, et al. In situ leukemic plasmacytoid dendritic cells pattern of chemokine receptors expression and in vitro migratory response. Leukemia. 2004;18(9):1491-8.

97. • Facchetti F. Plasmacytoid dendritic cell neoplasms. In: Orazi A et al., editors. Knowles neoplastic hematopathology. Philadelphia: Lippincott Williams \& Wilkins; 2013. This book chapter summarize clinical and biological features of PDC-derived neoplasms.

98. Jardin F, Ruminy P, Parmentier F, et al. TET2 and TP53 mutations are frequently observed in blastic plasmacytoid dendritic cell neoplasm. Br J Haematol. 2011;153(3):413-6.

99. Dijkman R, van Doorn R, Szuhai K, et al. Gene-expression profiling and array-based CGH classify CD4 + CD56+ hematodermic neoplasm and cutaneous myelomonocytic leukemia as distinct disease entities. Blood. 2007;109(4):1720-7.

100. Facchetti F, Pileri SA, Agostinelli C, et al. Cytoplasmic nucleophosmin is not detected in blastic plasmacytoid dendritic cell neoplasm. Haematologica. 2009;94(2):285-8.

101. Jardin F, Callanan M, Penther D, et al. Recurrent genomic aberrations combined with deletions of various tumour suppressor genes may deregulate the G1/S transition in CD4 + CD56+ haematodermic neoplasms and contribute to the aggressiveness of the disease. Leukemia. 2009;23(4):698-707.

102. Wiesner T, Obenauf AC, Cota C, et al. Alterations of the cellcycle inhibitors p27(KIP1) and p16(INK4a) are frequent in blastic plasmacytoid dendritic cell neoplasms. J Investig Dermatol. 2010;130(4):1152-7.

103. Dalle S, Beylot-Barry M, Bagot M, et al. Blastic plasmacytoid dendritic cell neoplasm: is transplantation the treatment of choice? Br J Dermatol. 2010;162(1):74-9.

104. Jacob MC, Chaperot L, Mossuz P, et al. CD4+ CD56+ lineage negative malignancies: a new entity developed from malignant early plasmacytoid dendritic cells. Haematologica. 2003;88 (8):941-55.

105. Cota C, Vale E, Viana I, et al. Cutaneous manifestations of blastic plasmacytoid dendritic cell neoplasm-morphologic and phenotypic variability in a series of 33 patients. Am J Surg Pathol. 2010;34 (1):75-87.

106. Defays A, David A, de Gassart A, et al. BAD-LAMP is a novel biomarker of nonactivated human plasmacytoid dendritic cells. Blood. 2011;118(3):609-17.

107. Feuillard J, Jacob MC, Valensi F, et al. Clinical and biologic features of CD4(+)CD56(+) malignancies. Blood. 2002;99 (5):1556-63.

108. Bekkenk MW, Jansen PM, Meijer CJ, et al. CD56+ hematological neoplasms presenting in the skin: a retrospective analysis of 23 new cases and 130 cases from the literature. Ann Oncol. 2004;15 (7):1097-108.

109. Dietrich S, Andrulis M, Hegenbart U, et al. Blastic plasmacytoid dendritic cell neoplasia (BPDC) in elderly patients: results of a treatment algorithm employing allogeneic stem cell transplantation with moderately reduced conditioning intensity. Biol Blood Marrow Transplant. 2011;17(8):1250-4.

110. Jegalian AG, Buxbaum NP, Facchetti F, et al. Blastic plasmacytoid dendritic cell neoplasm in children: diagnostic features and clinical implications. Haematologica. 2010;95(11):1873-9. 